\title{
Macroscopic and Fluorescent Discrimination of Adenosine Triphosphate via Selective Metallo-hydrogel Formation: A Visual, Practical, and Reliable Rehearsal toward Cellular Imaging
}

\author{
Weiwei Fang, ${ }^{\dagger}$ Cong Liu, ${ }^{\dagger}$ Fabiao Yu, ${ }^{\S}$ Yaoqi Liu, ${ }^{\dagger}$ Zhenhua $\mathrm{Li}^{\dagger}{ }^{\dagger}$ Lingxin Chen, ${ }^{*},{ }^{\S}$ Xiaoling Bao, ${ }^{*}, \mathrm{II}$ \\ and $\mathrm{Tao} \mathrm{Tu}^{*},+$,

\begin{abstract}
${ }^{\dagger}$ Department of Chemistry, Fudan University, 220 Handan Road, Shanghai 200433, China
${ }^{\ddagger}$ State Key Laboratory of Organometallic Chemistry, Shanghai Institute of Organic Chemistry, Chinese Academy of Sciences, Shanghai 200032, China

${ }^{\S}$ Key Laboratory of Coastal Environmental Processes and Ecological Remediation, The Research Center for Coastal Environmental Engineering and Technology, Yantai Institute of Coastal Zone Research, Chinese Academy of Sciences, Yantai 264003, China

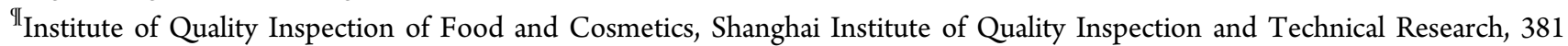
Cangwu Road, Shanghai 200233, China
\end{abstract}

\section{Supporting Information}

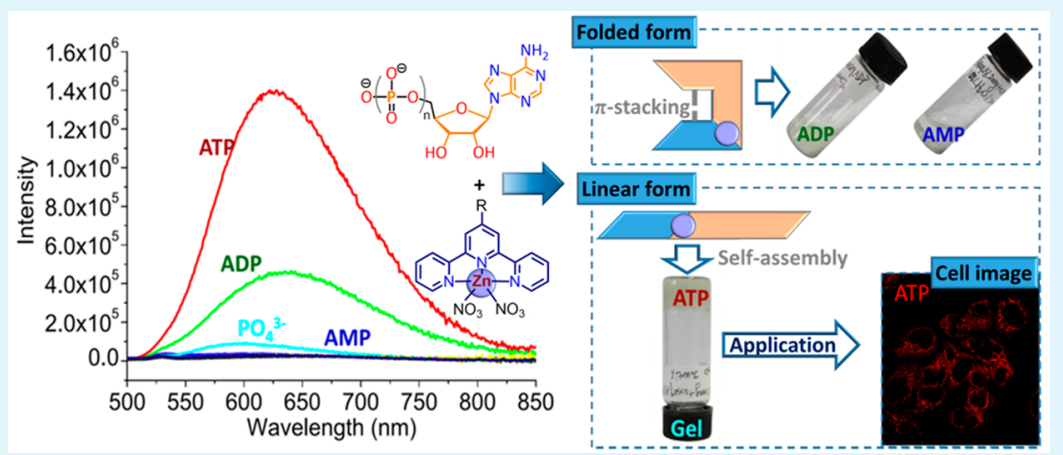

ABSTRACT: With use of simple terpyridine zinc nitrate complexes, intriguing visual recognition of adenosine triphosphate (ATP) via selective coordination assembly leading to two-component metallo-hydrogel formation has been realized. With intensive fluorescent study and density functional theory calculations, it may be inferred, besides the selective metal-ligand interaction between $\mathrm{Zn}$ center and phosphate groups, the intramolecular $\pi$-stacking between the planar nucleobases of ATP and the metal-hybrid aromatic ring of pincer complex strongly affected the geometry of the coordinated adducts and possible molecular self-assembly process, which constitute a completely new sensing strategy in comparison with the conventional approaches. Furthermore, in light of extreme sensitivity of pincer zinc complexes toward ATP at micromolar scale (1.85 $\mu \mathrm{M})$ and remarkable fluorescent enhancement (ca. 44-fold) upon ATP addition, the feasibility of the low cytotoxicity pincer zinc complexes in monitoring ATP in HeLa cells has been fulfilled with confocal fluorescence microscopy.

KEYWORDS: adenosine triphosphate, celluar imaging, fluorescence enhancement, metallo-hydrogel, visual recognition

\section{INTRODUCTION}

As an intriguing challenging task, the development of novel molecular sensing systems for substances of biological significance, especially under aqueous conditions, has recently received considerable attention. ${ }^{1}$ The difficulty of sensing is not only the competitive interaction of water molecules with the artificial sensor but also how to selectively amplify a weak signal of discrimination. ${ }^{2}$ For example, as one of the most important nucleotides, adenosine triphosphate (ATP) plays key roles in intracellular energy transfer and also functions as an extracellular signaling mediator in various metabolic processes. ${ }^{3,4}$ The deficiency of ATP is consequently correlative with a plethora of pathogenesis. ${ }^{5-7}$ However, the selective probing of ATP in the presence of other bioactive substances in physiological media is still challenging. Numerous artificial fluorescent receptors bearing functional groups readily forming hydrogen bonding have been consequently developed. ${ }^{8-12}$ In some cases, positively charged substitutions were introduced to strengthen the hydrogen-bonding effects to anions. The relatively low sensitivity and poor selectivity of sensing are usually observed due to the interference of the sugar moiety in ATP along with the competitive interaction of water, which

Received: May 16, 2016

Accepted: July 15, 2016

Published: July 15, 2016 
(a)

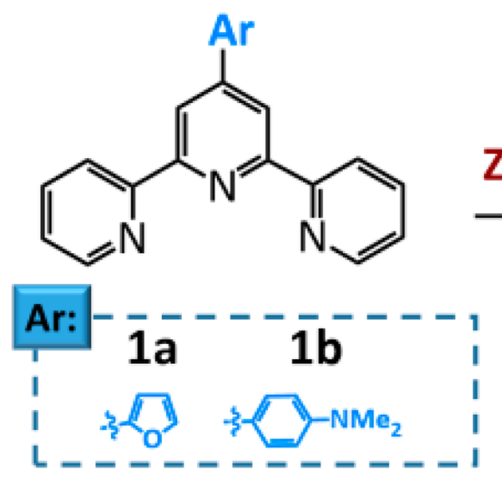

(b)

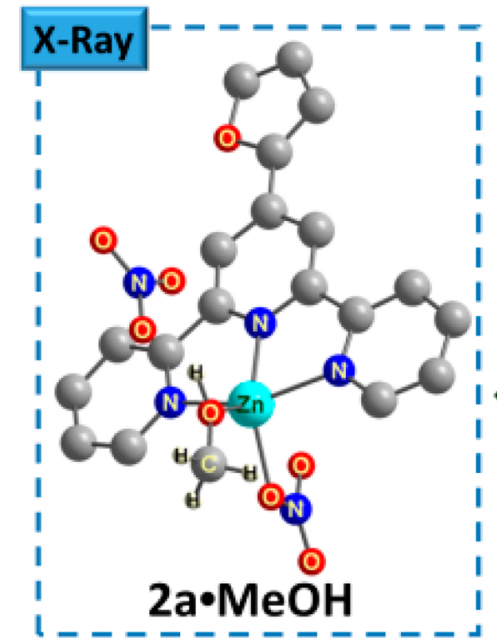

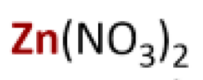

$\mathrm{MeOH}$

I

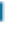

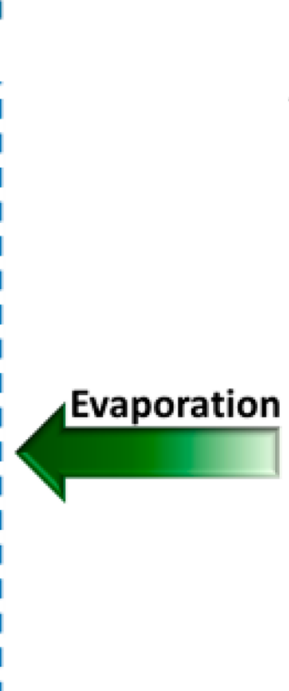

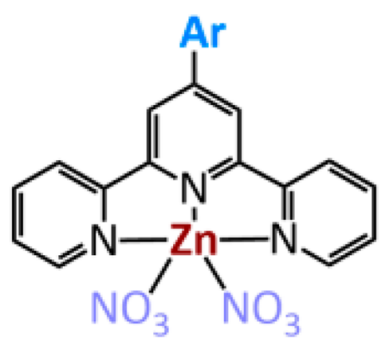

\section{$2 a$ and $2 b$}<smiles>CO[14CH2][14C@H](O)[14CH2][14CH2]O</smiles>

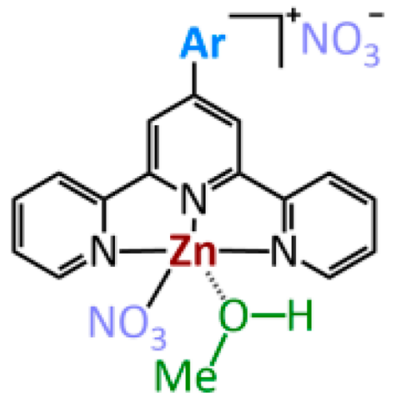

2a.MeOH

Figure 1. (a) Synthesis of pincer zinc complexes $\mathbf{2} \mathbf{a}$ and $\mathbf{2} \mathbf{b}$ and (b) the resulting crystal structure of $\mathbf{2 a} \cdot \mathrm{MeOH}$ obtained after direct evaporation.

limited their feasibility. ${ }^{13}$ When the coordination affinity of the phosphate anion to the various metal centers is taken into account, the metal-ligand coordination is considered as a second strategy to probe ATP. ${ }^{14-19}$ Several fluorescent monoand bimetallic complexes were synthesized, and applied in the molecular recognition of ATP along with other bioactive phosphates without selectivity. ${ }^{1,10,12,20}$ Despite these achievements, only a few examples of visual discrimination of ATP along with its homologues via colorimetric methods have been reported, ${ }^{21-25}$ and the specific protocol for ATP detection from a mixture containing adenosine diphosphate (ADP), adenosine monophosphate (AMP), and other phosphates is still regarded as an exteremelly challenging task due to their similar structures, especially under aqueous conditions.

Functional molecular gels represent one kind of smart soft matter, ${ }^{26,27}$ which recently also exhibit potential as a valuable platform for molecular recognition. ${ }^{28}$ Hamachi and co-workers first applied molecular organo-hydrogels as efficient supports to immobilize an artificial sensor for phosphate derivatives analysis in $2005 .^{29} \mathrm{Liu}$ and co-workers subsequently reported the visual discrimination of ATP in preference to ADP and AMP via cationic organogels collapse in alcoholic aqueous media, although the limit of detection was relatively high $(6.25 \times$ $\left.10^{-3} \mathrm{M}\right) \cdot{ }^{30}$ However, to the best of our knowledge, there are no reports of the molecular discrimination of ATP from other phosphates using selective metallo-hydrogels formation in physiological media as a sensor system. The incorporation of transition metals can endow the characteristics associated with the metals into the gel systems, and provide a good opportunity to subtly control the molecular assembly process and microscopic response to external stimuli. ${ }^{31-37}$ Our group recently demonstrated unprecedented visual discriminations of enantiomers, positional isomers, and mercapto analogues via selective phase transformation of molecular metallogels based on rational designed pincer complexes. ${ }^{38-42}$ Following our research interests in exploring the feasibility of metal pincer complexes in catalysis, sensing, and molecular switches, ${ }^{38-44}$ we sought to explore the possibility of selectively visual discrimination of ATP under the aqueous environment by using simple terpyridine-Zn(II) complexes, study the mechanism, and investigate their possible applicability toward cellular imaging.

\section{RESULTS AND DISCUSSION}

Initially, pincer zinc complexes $\mathbf{2 a}$ and $\mathbf{2} \mathbf{b}$ containing weakly bound nitrate anions (Figure 1a) were designed for ATP recognition. Complex 2a was readily obtained almost in a quantitative yield by reaction of 2-furyl terpyridine 1 a with $\mathrm{Zn}\left(\mathrm{NO}_{3}\right)_{2} \cdot 6 \mathrm{H}_{2} \mathrm{O}$ in methanol at room temperature for $24 \mathrm{~h}$. Transparent rectangular single crystals suitable for X-ray analysis were obtained by slow evaporation of the resulting methanol solution. As illustrated in Figure 1b, one nitrate anion was not coordinated to the zinc center of complex 2a; the oxygen atom of methanol solvent was coordinated instead. The ${ }^{1} \mathrm{H}$ NMR $\left(\mathrm{CD}_{3} \mathrm{OD}\right)$ spectrum study showed two sets of signals and suggested a dynamic equilibrium between the complexes $\mathbf{2 a}$ and $\mathbf{2 a} \cdot \mathbf{M e O H}$ in the solution state. The ratio of two complexes was slightly influenced by the variation of test temperature (Figures S38-S40 of the Supporting Information). Subsequently, the investigation on the gelation ability of 


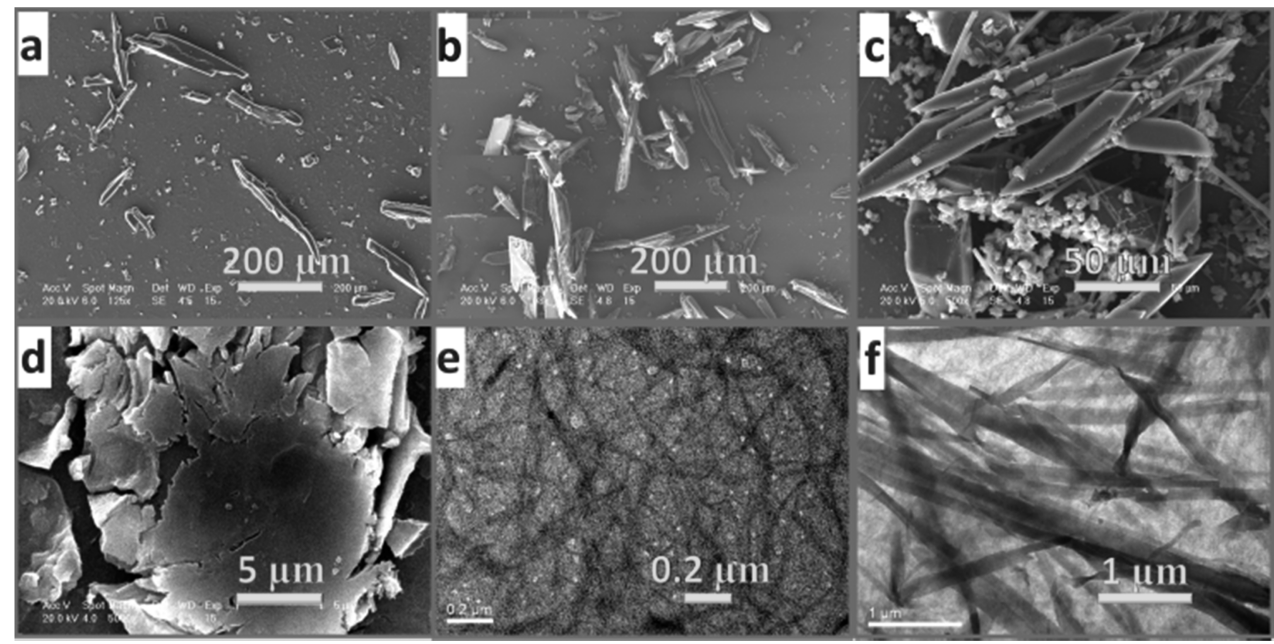

Figure 2. Scanning electron microscopic morphologies of (a) the precipitates of $2 \mathrm{a} / \mathrm{H}_{2} \mathrm{O}(2 \mathrm{wt} \%),(\mathrm{b})$ [ $2 \mathrm{a}+0.25$ equiv of $\left.\mathrm{AMP}\right] / \mathrm{H}_{2} \mathrm{O}(2 \mathrm{wt} \%)$, (c) $[2 \mathrm{a}+0.25$ equiv of $\mathrm{ADP}] / \mathrm{H}_{2} \mathrm{O}(2 \mathrm{wt} \%)$, and (d) gel $[2 \mathrm{a}+0.25$ equiv of ATP $] / \mathrm{H}_{2} \mathrm{O}(2 \mathrm{wt} \%)$. TEM images of $(\mathrm{e})$ gel $[2 \mathrm{a}+0.25$ equiv of $\mathrm{ATP}] / \mathrm{H}_{2} \mathrm{O}(2 \mathrm{wt} \%)$ and (f) gel $\left[2 \mathrm{a}+0.5\right.$ equiv of $\left.\mathrm{K}_{3} \mathrm{PO}_{4}\right] / \mathrm{H}_{2} \mathrm{O}(1 \mathrm{wt} \%)$.

complex $\mathbf{2} \mathbf{a}$ and $\mathbf{2} \mathbf{b}$ in a number of organic solvents as well as pure water was therefore carried out. No gel was formed after regular heating and cooling procedures for the gel preparation; $^{42}$ precipitates or clear solutions were obtained instead (Table S1). Nucleotides like ATP contain phosphate, sugar, and planar nucleobase, three major fragments, which not only may bind to the metal center due to the strong affinity coefficient of phosphate group to zinc center ${ }^{15}$ but also may form hydrogen bonding and $\pi-\pi$ interactions to facilitate molecular self-assembly leading to the gel formation. Therefore, ATP and its analogues were involved in the gelation tests. Only solution or precipitates were obtained in the most selected organic solutions (such as $\mathrm{MeOH}$, dimethylsulfoxide, and dimethylformamide). An opaque white two-component metallo-hydrogel was finally obtained by cooling a hot aqueous mixture containing 2 wt \% complex $2 \mathrm{a}$ and 0.25 equiv of ATP. However, the addition of ADP and AMP under the identical operation did not result in metallo-hydrogel formation, and only the white precipitates were observed (Table S2). Although the samples containing $\mathbf{2 b}$ and 0.25 equiv of $\mathrm{AMP}, \mathrm{ADP}$, or ATP ( 2 wt \%) were not completely dissolved after heating under the identical gelation operation, partial gel formation was observed with the soluble part of the sample containing ATP. The observation of these differences allows the first selective visual recognition of ATP out of its bioactive homologous via selective gel formation.

To confirm this macroscopic distinguishable phenomenon, the microscopic morphology study on the samples of gelation tests with pincer complex 2a were performed with scanning electron microscopy (SEM) and transmission electron microscopy (TEM). The precipitates of $2 \mathrm{a} / \mathrm{H}_{2} \mathrm{O}$ (2 wt \%) revealed irregular bulky crystalline rods (Figure $2 \mathrm{a}$ ). Similar but dense crystalline rods were observed with the precipitate of [ $2 \mathrm{a}$ +0.25 equiv of $\mathrm{AMP}] / \mathrm{H}_{2} \mathrm{O}$ (2 wt $\%$, Figure $2 \mathrm{~b}$ ). When $\mathrm{ADP}$ was involved, the images containing microcrystalline blades along with cubic crystals and fibers were found (Figure 2c). In contrast, amorphous sheets were observed in the SEM image of the gel $[2 \mathrm{a}+0.25$ equiv of ATP $] / \mathrm{H}_{2} \mathrm{O}(2 \mathrm{wt} \%$, Figure $2 \mathrm{~d})$, which consisted of very condensed cross-linked nanofibers, further proved by using TEM study (Figure 2e). Therefore, the selective molecular recognition of ATP from its homologues appeared due to the long and dense nanofibers formed by the coordination adduct containing complex 2a and ATP via selfassembly, which were able to immobilize water molecules within the network to form stable metallo-hydrogels.

With these exciting results in hand, a set of control experiments was carried out. A number of phosphates, including sodium pyrophosphate (PPi), potassium phosphate $\left(\mathrm{K}_{3} \mathrm{PO}_{4}\right)$, dipotassium phosphate $\left(\mathrm{K}_{2} \mathrm{HPO}_{4}\right)$, potassium phosphate monobasic $\left(\mathrm{KH}_{2} \mathrm{PO}_{4}\right)$, etc., were selected to probe the role of the phosphate group during the gelation process (Table S3). Upon the addition of 1 equiv of $\mathrm{K}_{3} \mathrm{PO}_{4}$, complex $2 \mathrm{a}$ or $\mathbf{2 b}$ was difficult to dissolve in water even under severe heating. Decreasing the amount of $\mathrm{K}_{3} \mathrm{PO}_{4}$ to 0.5 equiv resulted in the formation of a translucent white gel $[2 a+0.5$ equiv of $\left.\mathrm{K}_{3} \mathrm{PO}_{4}\right] / \mathrm{H}_{2} \mathrm{O}$ (1 wt \%) after cooling the heated mixture. To our delight, even with 0.1 equiv of $\mathrm{K}_{3} \mathrm{PO}_{4}$, a robust gel was still obtained. When the concentration of $2 \mathrm{a}$ was increased to $2 \mathrm{wt}$ $\%$, the sample could not be completely dissolved by heating; however, the dissolved part also formed a gel after cooling and resting operation. TEM revealed very dense nanofibers which was much broader than that observed in the gel $[2 a+0.25$ equiv of ATP $] / \mathrm{H}_{2} \mathrm{O}$ (2 wt \%, Figure $2 \mathrm{e}, \mathrm{f}$ ). To exclude ion effects, a series of potassium and sodium salts containing other anions were used in the control experiments. The gel formation only occurred in the samples containing $\mathrm{K}_{2} \mathrm{HPO}_{4}$ or $\mathrm{KH}_{2} \mathrm{PO}_{4}$; other salts all resulted in precipitates or solutions under the identical gelation operation (Table S3). This outcome indicated the key role of phosphates during the gel formation, which was also consistent with previous studies. Therefore, this system can act as a simple, straightforward, and practical visual discrimination of phosphates from other anions.

Subsequently, a study of thermodynamic property of the phosphates containing metallo-hydrogels was carried out. The gel-to-sol phase-transition temperatures $\left(T_{\mathrm{g}}\right)$ of the selected gel samples were determined by the "test-tube-inversion method" ${ }^{45}$ In comparison with our previous reported metallogels, ${ }^{38-41}$ all the gel samples were relatively robust and survived the heating over $100^{\circ} \mathrm{C}$. For instance, the $T_{\mathrm{g}}$ value of gel $\left[2 \mathrm{a}+0.5\right.$ equiv of $\left.\mathrm{K}_{3} \mathrm{PO}_{4}\right] / \mathrm{H}_{2} \mathrm{O}(1 \mathrm{wt} \%)$ was $115^{\circ} \mathrm{C}$. The plot of $T_{\mathrm{g}}$ was steadily increased along with the addition of $\mathrm{K}_{3} \mathrm{PO}_{4}$ from 0.1 to 0.5 equiv. When the phosphate amount was further increased to 0.6 equiv, the $T_{\mathrm{g}}$ was decreased to $103{ }^{\circ} \mathrm{C}$ (Figure S11). Similar results were also observed with the gel 


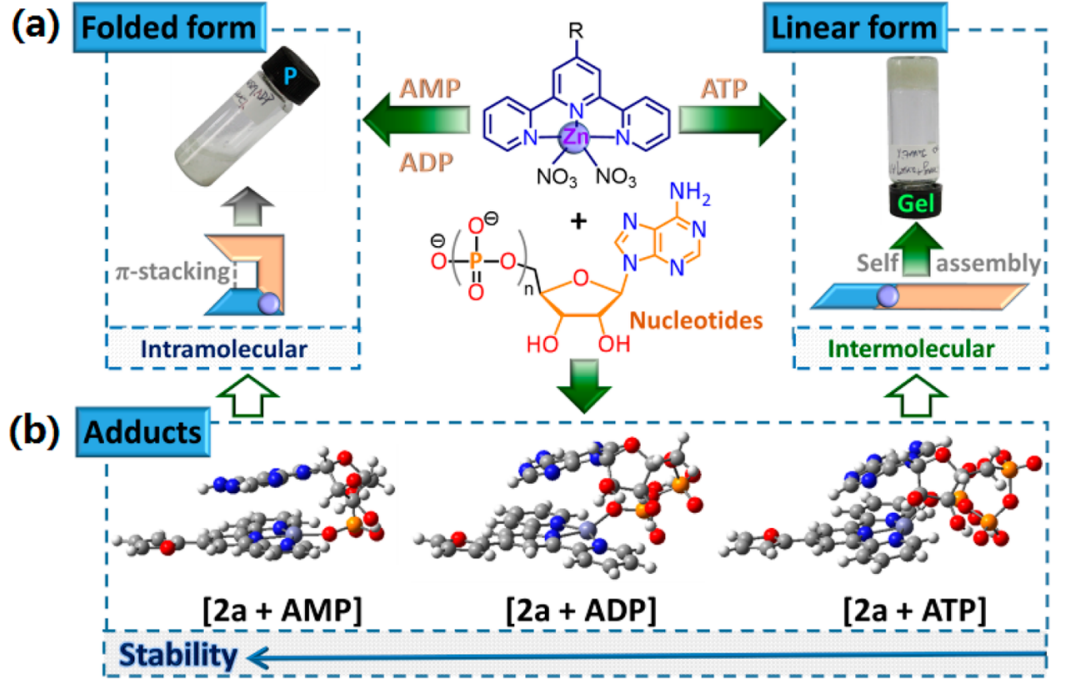

Figure 3. (a) Visual discrimination of ATP out of its homologues via selective gel formation; (b) calculated geometries of three adducts formed by complexes 2 a with AMP, ADP, and ATP, respectively.

$[2 \mathrm{a}+\mathrm{ATP}] / \mathrm{H}_{2} \mathrm{O}(2 \mathrm{wt} \%)$, which indicated the amount of ATP exhibited a strong impact on the thermo-stability of metallogel. The addition of 0.25 equiv of ATP resulted in the highest $T_{\mathrm{g}}$ value (Figure $\mathrm{S} 10$ ).

A series of rheological studies were performed to quantify the gels' mechanical and thixotropic characteristics. In the case of gel $[2 a+0.25$ equiv of ATP $](2$ wt $\%)$, the elastic storage modulus $\left(G^{\prime}\right)$ was much greater than the loss modulus $\left(G^{\prime \prime}\right)$ when the shear strain was $<4.0 \%$ (a value of yielding point). Beyond this level, the gel gave a strain overshoot: ${ }^{46}$ when the $G^{\prime}$ value was going to further decrease, the value $G^{\prime \prime}$ would increase first and then decrease during the range of $6.3 \%-$ $20.0 \%$. At large strain amplitudes ( $>13 \%)$, the gel showed a catastrophic disruption accompanied by a reversal of the viscoelastic signal $\left(G^{\prime \prime}>G^{\prime}\right)$ (Figure S12). Subsequently, the shear strain of $1.0 \%$ was applied to characterize viscoelastic behavior of the gel samples with increasing angular frequency. As shown in Figure S13, the dynamic frequency sweep rheometry data revealed a kind of classic shear viscosity curve. The slightly increasing values of $G^{\prime}$ and almost no change in $G^{\prime \prime}$ along with the steadily increasing frequency suggested that the energy storage process occurred without obvious energy dissipation and the metallo-hydrogel possessed very good elasticity. The complex viscosity $\left(\eta^{*}\right)$ was decreased along with the increasing frequency, indicating the shearing thinning phenomena occurred and thixotropic character of the gel. Similar results were obtained for the gel $[2 a+0.5$ equiv of $\left.\mathrm{K}_{3} \mathrm{PO}_{4}\right]$ (1 wt \%); however, the strength of relative parameter was much lower (Figures S14 and S15).

The X-ray crystal structure analysis of complex $2 \mathrm{a} \cdot \mathrm{MeOH}$ revealed planar pincer complex $\mathbf{2 a}$ efficiently packed via two types of intermolecular $\pi$-stacking (Figure S17). Two molecules interacted to form a unit via weak $\pi-\pi$ interaction between the furan ring and the center pyridine ring of the second molecule (3.629 $\AA$ ). The units were further assembled into linear aggregates via the second $\pi-\pi$ interaction between the furan ring and the side pyridines of the second units (3.627 $\AA$ ). In combination with the results obtained by X-ray diffraction (XRD) of the xerogels $[\mathbf{2 a}+0.25$ equiv of ATP $]$ and $[2 \mathbf{a}+0.5$ equiv of $\left.\mathrm{K}_{3} \mathrm{PO}_{4}\right]$, the signals at $2 \theta$ around $23^{\circ}$ with corresponding distance at 3.7-3.9 $\AA$, we may suggest that the intermolecular $\pi$-stacking and metal-metal interactions of the adducts formed by the pincer complex and phosphates may be responsible for the molecular self-assembly leading to the gel formation (Figures S18 and S19). However, the difference between the thermal and mechanical characteristics of the gels containing ATP and $\mathrm{K}_{3} \mathrm{PO}_{4}$ indicates additional interactions may exist during the self-assembly process of complex $2 \mathrm{a}$ with ATP.

Density functional theory (DFT) calculation was therefore applied to further explore the possible interactions of three coordination adducts formed by complex $2 \mathrm{a}$ with AMP, ADP, and ATP, respectively, with the basis set of $6-31+G(d) .{ }^{47}$ The results indicated that intramolecular $\pi$-stacking played an important role in the geometry of three coordination adducts. Because of the intramolecular $\pi$-stacking between planar nucleobase moiety and the metal-hybrid aromatic ring of complex 2a, three adducts all seem to adapt in the folded geometries (Figure $3 \mathrm{~b}$ ). However, the calculated energies at $298 \mathrm{~K}$ for three folded coordination adducts formed by AMP, $\mathrm{ADP}$, and ATP were $-7.6,0.1$, and $2.2 \mathrm{kcal} / \mathrm{mol}$, respectively. Mulliken charge analysis indicated that the charges on the terminal oxygen atoms of AMP were the most negative, while those of ATP were the least negative in the folded forms. In consideration that the coordination between zinc and oxygen was ionic, more negative charge should be on the oxygen atom, which would result in a stronger coordination bond leading to the adduct formation. It would be expected that the coordination adducts formed by complex $\mathbf{2 a}$ with AMP or $\mathrm{ADP}$ intended to adopt folded forms, which were unfavorable for the formation of metallogel via molecular self-assembly. In the case of the coordination adduct formed by complex $2 \mathbf{a}$ and ATP, the intramolecular $\pi$-stacking between the two aromatic rings was relatively weaker; to form stable adduct, liner geometry may be preferred, which may allow the possibility of intermolecular self-assembly leading to the gel formation.

At last, UV-vis and fluorescent studies were carried out, which are considered as powerful tools to probe the mechanism for molecular recognition. ${ }^{48,49}$ No apparent changes were observed in the UV-vis spectra of $2 \mathrm{a}\left(3.69 \times 10^{-5} \mathrm{M}\right)$ after 0.25 equiv of $\mathrm{ATP}, \mathrm{ADP}, \mathrm{AMP}$, or 0.5 equiv of selected potassium salts addition (Figures S21 and S22). At 298 K, 

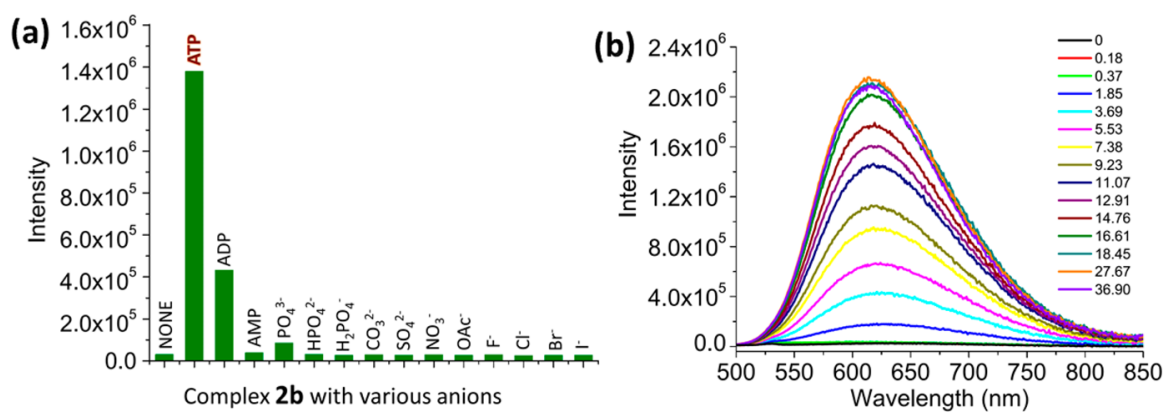

Figure 4. (a) Emission spectra of $2 \mathbf{b}\left(3.69 \times 10^{-5} \mathrm{M}, \lambda_{\mathrm{ex}}=448 \mathrm{~nm}\right)$ in fresh pure deionized water with $\mathrm{pH}$ at 7 with 0.25 equiv of AMP, ADP, ATP, or 0.5 equiv of different anions and (b) $2 \mathbf{b}\left(3.69 \times 10^{-5} \mathrm{M}\right)$ in fresh pure deionized water with $\mathrm{pH}$ at 7 with various concentrations $(\mu \mathrm{M})$ of ATP $\left(\lambda_{\mathrm{ex}}=448 \mathrm{~nm}\right)$.

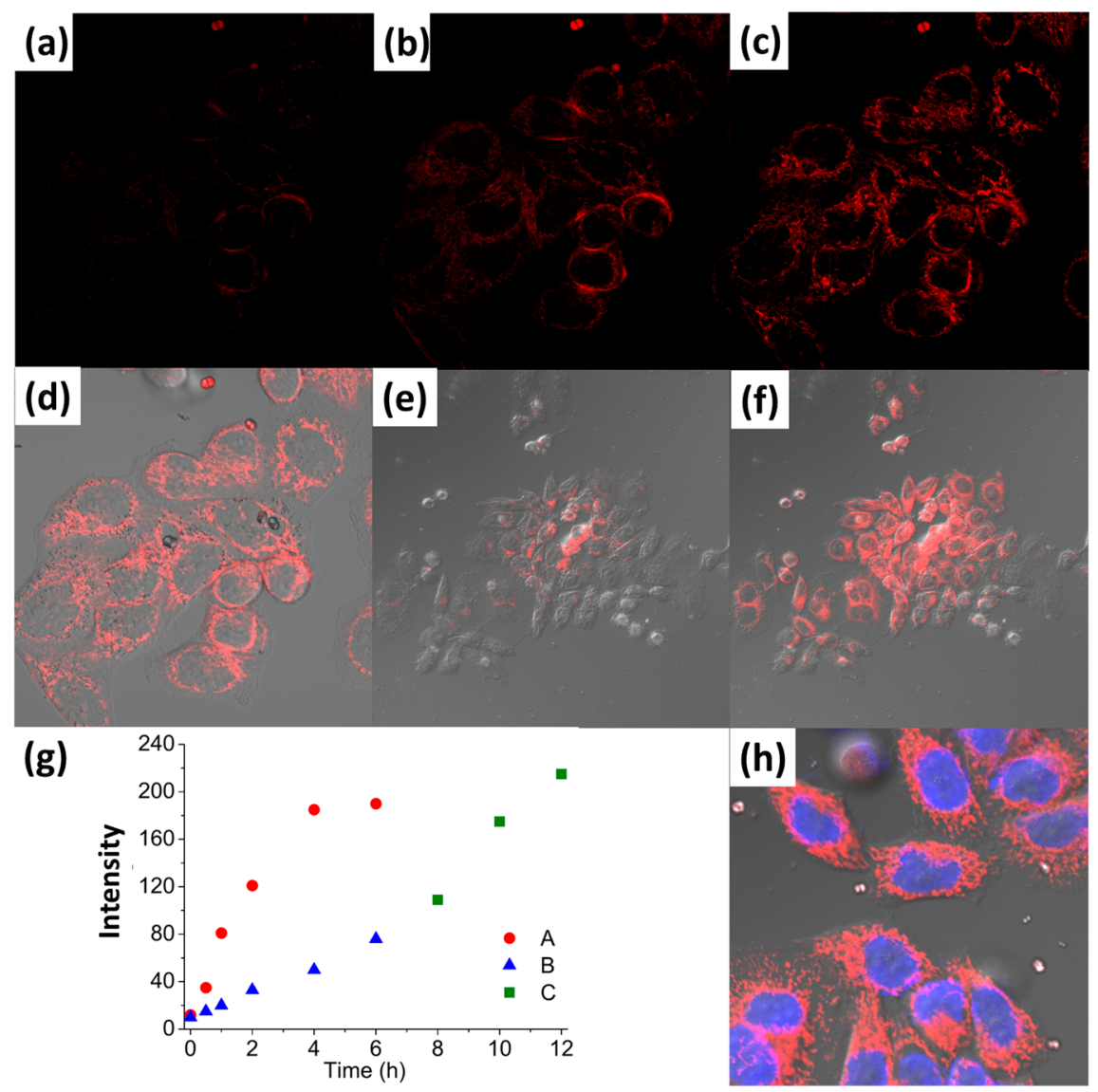

Figure 5. Confocal fluorescence microscopy images of (a) HeLa cells incubated with $5 \mu \mathrm{M}$ complex $2 \mathbf{b}$ for 15 min (control) and then further incubated with $50 \mu \mathrm{M}$ ATP (b) for $1 \mathrm{~h}$ and (c) for $6 \mathrm{~h}$ (red channel: $\lambda_{\mathrm{ex}}=488 \mathrm{~nm}$; fluorescence collected window: $550-750 \mathrm{~nm}$ ). (d) Overlay image of frames (c) with bright field image (scale bar $=10 \mu \mathrm{m}$ ); (e) overlay image of complex $2 \mathbf{b}$ existed HeLa cells (control) incubated for $6 \mathrm{~h}$ with bright field image; and (f) overlay image of complex $\mathbf{2 b}$ existed HeLa cells (control) incubated for $6 \mathrm{~h}$ and then adding $50 \mu \mathrm{M}$ ATP incubated for another 6 $\mathrm{h}$, with bright field image (scale bar $=10 \mu \mathrm{m}) ;(\mathrm{g})$ time-dependent fluorescence intensity of complex $\mathbf{2 b}$ existed HeLa cells in the presence of $50 \mu \mathrm{M}$ ATP (A, for 0-6 h) and complex $2 \mathrm{~b}$ existed HeLa cells (B, for 0-6 h) and then adding $50 \mu \mathrm{M}$ ATP (C, for 6-12 h); and (h) HeLa cells in the colocalization experiment (scale bar $=10 \mu \mathrm{m}$.

pincer complex $2 \mathbf{b}\left(3.69 \times 10^{-5} \mathrm{M}\right)$ exhibited yellow color and three major bands at 284, 323, and $405 \mathrm{~nm}$ were observed. According to the previous reports, ${ }^{50}$ the lowest energy absorption bands of complex $\mathbf{2} \mathbf{b}$ at $405 \mathrm{~nm}$ (black line) was assigned to the intraligand charge transfer (ILCT) (Figure S23). Although only slightly red shifts (ca. $2 \mathrm{~nm}$ ) were observed with three samples after ATP (purple line), ADP (green line), or AMP (red line) addition, the intensity of all three was weaker than that of pure complex $2 a$, especially in the case of ATP. However, no obvious change in the spectra was found with other anions (Figure S24).

In light of gel $[2 \mathrm{a}+0.25$ equiv of ATP $]$ being weak fluorescent, fluorescent study was further investigated. Upon excitation at $284 \mathrm{~nm}$, planar compound 2a exhibited a strong fluorescent emission at $450 \mathrm{~nm} .{ }^{50}$ In contrast to the selected anions, which showed no observable alternation (Figure S21), the addition of 0.25 equiv of ATP resulted in a slight but noticeable quenching of the emission at $450 \mathrm{~nm}$ (11\%, Figure S28). Because of the photoinduced electron transfer (PET) 
effect of dimethylamino-phenyl group, when the aqueous solution of complex $\mathbf{2 b}$ was excited at $448 \mathrm{~nm}$, only very weak fluorescent emission was observed at $617 \mathrm{~nm}$, which may be considered as a better sensor system to study the influence after nucleotides addition. To our delight, a dramatic fluorescence enhancement (ca. 44-fold) at $617 \mathrm{~nm}$ was found in the mixture of complex $2 \mathbf{b}$ and 0.25 equiv of ATP, whereas much less enhancement (ca. 14-fold) was observed after ADP addition and almost no change was found with the sample containing AMP and other anions (Figure 4a). The linear form geometry (Figure $3 a$ ) of the coordination adduct formed by complex $\mathbf{2 b}$ and ATP may be suitable for further molecular self-assembly resulted in fluorescence enhancement due to aggregationinduced emission (AIE). Subsequently, other biological species including selected amino acids and peptide were also involved; no apparent influence on the fluorescence was observed (Figure S30), which may highlight its potential application toward cell imaging. The detection limit of ATP in water with pincer complex $\mathbf{2 b}$ was found at micromolar scale (ca. $1.85 \mu \mathrm{M}$, Figure $4 \mathrm{~b}$ ), which was much lower than the average concentration of ATP in mammalian cells. ${ }^{51}$ Additionally, a good linearity varied the concentration of ATP from 0 to $18.45 \mu \mathrm{M}$ and relative fluorescent intensity of complex $2 \mathbf{b}$ at $617 \mathrm{~nm}$ was observed (Figure S32).

\section{BIOLOGICAL APPLICATION}

To test the cytotoxicity of complex $\mathbf{2 b}$, a standard 3-(4,5dimethyl-2-thiazolyl)-2,5-diphenyl-2-H-tetrazolium bromide (MTT) assay was performed (Figure S36). The $\mathrm{IC}_{50}$ of complex 2 b was $120 \mu \mathrm{M}$, which indicated its low cytotoxicity under the test conditions. With use of confocal fluorescence microscopy, the possibility of complex $\mathbf{2 b}$ to detect ATP in HeLa cells was carried out. HeLa cells were incubated in the presence of $5 \mu \mathrm{M}$ complex $\mathbf{2 b}$ for $15 \mathrm{~min}$ at $37^{\circ} \mathrm{C}$ and then washed with Dulbecco's modified eagle medium (DMEM) three times to remove the excess complex $\mathbf{2 b}$. The cells were further incubated in fresh cell culture medium (DMEM $+20 \%$ FBS) for the visual detection of ATP existing in the HeLa cells. As a control, the cells only showed very faint fluorescence without external addition of ATP (Figure 5a). Then $50 \mu \mathrm{M}$ ATP was added into the biosystem (A), and after being incubated for $1 \mathrm{~h}$, the cells displayed a significant fluorescent enhancement in the intensity (Figure 5b). To study the relationship of fluorescence enhancement of $[\mathbf{2 b}+\mathrm{ATP}]$ along with the incubated duration, the time-dependent fluorescence intensity was monitored for an additional $5 \mathrm{~h}$. As shown in Figure $5 \mathrm{~g}-\mathrm{A}$, the fluorescence intensity gradually increased and arrived at a plateau after $4 \mathrm{~h}$, which featured a 16-fold fluorescent enhancement (Figure $5 \mathrm{c}, \mathrm{d}$ and $5 \mathrm{~g}-\mathrm{I}$ ). In the case of no external ATP addition system (B), only a moderate enhancement (8-fold) was observed after $6 \mathrm{~h}$ of incubation (Figure $5 \mathrm{e}$ and $5 \mathrm{~g}-\mathrm{B}$ vs $5 \mathrm{~g}-\mathrm{A}$ ), which demonstrated that complex $\mathbf{2 b}$ can efficiently detect the original ATP in the HeLa cells. After $50 \mu \mathrm{M}$ ATP was added to the system (C), further enhancement (ca. 2.3-fold) in fluorescence intensity was also observed after incubation for an additional $6 \mathrm{~h}$ (Figure $5 \mathrm{f}$ and $5 g-C)$. The aforementioned results suggested that complex $\mathbf{2 b}$ was photostable and showed strong fluorescent enhancement within biological media, which also confirmed the applicability of complex $\mathbf{2 b}$ for the ATP detection in the living cells. In addition, the colocalization experiment was also implemented with the HeLa cells containing Hoechst 33342, which revealed that the targeting position of complex $\mathbf{2} \mathbf{b}$ toward ATP was mainly in cytoplasm (Figure 5h). Furthermore, according to the colocalization experiment of HeLa cells in the presence of Cy7 (mitochondria tracker) and complex $\mathbf{2 b}$, the fluorescence was actually distributed in mitochondria of the cell (Figure S36). This result could be further confirmed by flow cytometric analysis of isolated mitochondria (Figure S37), indicating a new and potentially powerful protocol for real-time imaging mitochondrial ATP changes in cells.

\section{CONCLUSIONS}

A selective macroscopic and fluorescent recognition of ATP from its homologues was successfully developed by using simple terpyridine zinc complexes via selective metallohydrogel formation. After detailed thermodynamic characterization, rheology, microscopy, and XRD studies of the resulting metallo-hydrogels, the plausible mechanism of this intriguing selective recognition was intensively investigated. With use of fluorescent study and DFT calculations, unlike the conventional molecular sensing strategies, along with the coordination ability of phosphate group to the zinc center, the intramolecular $\pi$ stacking between the planar nucleobases of ATP and the metalhybrid aromatic ring of pincer complex strongly affected the geometry of the coordinated adducts and possible molecular self-assembly process, which may lead to the selective metallohydrogel formation and remarkable fluorescent enhancement (ca. 44-fold), therefore, providing a new approach for selective ATP discrimination. In consideration that cytotoxicity of complex $\mathbf{2} \mathbf{b}$ and the detectable concentration of ATP in the water, both are relatively low; the potential application of this simple zinc pincer complex in monitoring ATP in HeLa cells has been successfully realized, which further supported that the visual discrimination of ATP via selective metallogel formation could be considered as a visible, practical, and reliable in vitro rehearsal toward celluar imaging.

\section{ASSOCIATED CONTENT}

\section{S Supporting Information}

The Supporting Information is available free of charge on the ACS Publications website at DOI: 10.1021/acsami.6b05804.

Synthetic detail, ${ }^{1} \mathrm{H}$ NMR, ${ }^{13} \mathrm{C}$ NMR, and ESI-MS spectra, single-crystal study (CCDC 1060488), sol-gel transition temperature, viscoelasticity and XRD study, $\mathrm{UV} /$ vis and fluorescent spectra, SEM and TEM morphologies, and cellular imaging (PDF)

\section{AUTHOR INFORMATION}

\section{Corresponding Authors}

*E-mail: taotu@fudan.edu.cn (T.T.).

*E-mail: 1xchen@yic.ac.cn (L.C.).

*E-mail: baoxl@sqi.org.cn (X.B.).

\section{Author Contributions}

T.T. and W.F. conceived and designed the experiments; W.F. performed the synthesis and experiments; C.L., Y.L., and X.B. contributed to the data confirmation and analysis; Z.L. performed the DFT calculations; F.Y. and L.C. contributed to the cell image test; all authors discussed the results; T.T. and W.F. wrote the paper; T.T. supervised the work.

\section{Funding}

The National Natural Science Foundation of China (No. 91127041, 21172045, and 21572036). 


\section{Notes}

The authors declare no competing financial interest.

\section{ACKNOWLEDGMENTS}

Financial support from the National Natural Science Foundation of China (No. 91127041, 21172045, 21405172, and 21572036), the Shanghai International Cooperation Program (14230710600), the Doctoral Fund of Ministry of Education of China (20130071110032), Ministry of Science and Technology of China (2016YFA0202902), the Shanghai Leading Academic Discipline Project (B108), and Department of the People's Republic of Chemistry Fudan University is gratefully acknowledged.

\section{REFERENCES}

(1) Zhou, Y.; Xu, Z.; Yoon, J. Fluorescent and Colorimetric Chemosensors for Detection of Nucleotides, FAD and NADH: Highlighted Research During 2004-2010. Chem. Soc. Rev. 2011, 40, 2222-2235.

(2) Knowles, J. R. Enzyme-Catalyzed Phosphoryl Transfer Reactions. Annu. Rev. Biochem. 1980, 49, 877-919.

(3) Gourine, A. V.; Llaudet, E.; Dale, N.; Spyer, K. M. ATP is a Mediator of Chemosensory Transduction in the Central Nervous System. Nature 2005, 436, 108-111.

(4) Dennis, P. B.; Jaeschke, A.; Saitoh, M.; Fowler, B.; Kozma, S. C.; Thomas, G. Mammalian TOR: a Homeostatic ATP Sensor. Science 2001, 294, 1102-1105.

(5) Bush, K. T.; Keller, S. H.; Nigam, S. K. Genesis and Reversal of the Ischemic Phenotype in Epithelial Cells. J. Clin. Invest. 2000, 106, 621-626.

(6) Przedborski, S.; Vila, M. MPTP: A Review of Its Mechanisms of Neurotoxicity. Clin. Neurosci. Res. 2001, 1, 407-418.

(7) Harkness, R. A.; Saugstad, O. D. The Importance of the Measurement of ATP Depletion and Subsequent Cell Damage with an Estimate of Size and Nature of the Market for a Practicable Method: a Review Designed for Technology Transfer. Scand. J. Clin. Lab. Invest. 1997, 57, 655-672.

(8) Li, X.; Guo, X.; Cao, L.; Xun, Z.; Wang, S.; Li, S.; Li, Y.; Yang, G. Water-Soluble Triarylboron Compound for ATP Imaging in Vivo Using Analyte-induced Finite Aggregation. Angew. Chem., Int. Ed. 2014, 53, 7809-7813.

(9) Ahmed, N.; Shirinfar, B.; Youn, I. S.; Bist, A.; Suresh, V.; Kim, K. S. A Highly Selective Fluorescent Chemosensor for Guanosine-5'Triphosphate via Excimer Formation in Aqueous Solution of Physiological pH. Chem. Commun. 2012, 48, 2662-2664.

(10) Hargrove, A. E.; Nieto, S.; Zhang, T.; Sessler, J. L.; Anslyn, E. V. Artificial Receptors for the Recognition of Phosphorylated Molecules. Chem. Rev. 2011, 111, 6603-6782.

(11) Xu, Z.; Singh, N. J.; Lim, J.; Pan, J.; Kim, H. N.; Park, S.; Kim, K. S.; Yoon, J. Unique Sandwich Stacking of Pyrene-Adenine-Pyrene for Selective and Ratiometric Fluorescent Sensing of ATP at Physiological pH. J. Am. Chem. Soc. 2009, 131, 15528-15533.

(12) Hirsch, A. K. H.; Fischer, F. R.; Diederich, F. Phosphate Recognition in Structural Biology. Angew. Chem., Int. Ed. 2007, 46, 338-352.

(13) Neelakandan, P. P.; Hariharan, M.; Ramaiah, D. Synthesis of a Novel Cyclic Donor-Acceptor Conjugate for Selective Recognition of ATP. Org. Lett. 2005, 7, 5765-5768.

(14) Schäferling, M.; Ääritalo, T.; Soukka, T. Multidentate Europium Chelates As Luminoionophores for Anion Recognition: Impact of Ligand Design on Sensitivity and Selectivity; and Applicability to Enzymatic Assays. Chem. - Eur. J. 2014, 20, 5298-5308.

(15) Zhang, M.; Ma, W.-J.; He, C.-T.; Jiang, L.; Lu, T.-B. Highly Selective Recognition and Fluorescence Imaging of Adenosine Polyphosphates in Aqueous Solution. Inorg. Chem. 2013, 52, 48734879.
(16) Pathak, R. K.; Hinge, V. K.; Rai, A.; Panda, D.; Rao, C. P. IminoPhenolic-Pyridyl Conjugates of Calix [4] arene $\left(\mathrm{L}_{1}\right.$ and $\left.\mathrm{L}_{2}\right)$ as Primary Fluorescence Switch-On Sensors for $\mathrm{Zn}^{2+}$ in Solution and in HeLa Cells and the Recognition of Pyrophosphate and ATP by $\left[\mathrm{ZnL}_{2}\right]$. Inorg. Chem. 2012, 51, 4994-5005.

(17) Rao, A. S.; Kim, D.; Nam, H.; Jo, H.; Kim, K. H.; Ban, C.; Ahn, K. H. A Turn-On Two-Photon Fluorescent Probe for ATP and ADP. Chem. Commun. 2012, 48, 3206-3208.

(18) Xu, Z.; Spring, D. R.; Yoon, J. Fluorescent Sensing and Discrimination of ATP and ADP Based on a Unique Sandwich Assembly of Pyrene-Adenine-Pyrene. Chem. - Asian J. 2011, 6, 21142122.

(19) Mahato, P.; Ghosh, A.; Mishra, S. K.; Shrivastav, A.; Mishra, S.; Das, A. Zn(II) Based Colorimetric Sensor for ATP and Its Use as a Viable Staining Agent in Pure Aqueous Media of $\mathrm{pH}$ 7.2. Chem. Commun. 2010, 46, 9134-9136.

(20) Kim, S. K.; Lee, D. H.; Hong, J.-I.; Yoon, J. Chemosensors for Pyrophosphate. Acc. Chem. Res. 2009, 42, 23-31.

(21) Zapata, F.; Caballero, A.; Espinosa, A.; Tárraga, A.; Molina, P. Cation Coordination Induced Modulation of the Anion Sensing Properties of a Ferrocene-Imidazophenanthroline Dyad: Multichannel Recognition from Phosphate-Related to Chloride Anions. J. Org. Chem. 2008, 73, 4034-4044.

(22) Jose, D. A.; Mishra, S.; Ghosh, A.; Shrivastav, A.; Mishra, S. K.; Das, A. Colorimetric Sensor for ATP in Aqueous Solution. Org. Lett. 2007, 9, 1979-1982.

(23) Li, C.; Numata, M.; Takeuchi, M.; Shinkai, S. A Sensitive Colorimetric and Fluorescent Probe Based on a Polythiophene Derivative for the Detection of ATP. Angew. Chem., Int. Ed. 2005, 44, 6371-6374.

(24) Sancenón, F.; Descalzo, A. B.; Martínez-Máñez, R.; Miranda, M. A.; Soto, J. A Colorimetric ATP Sensor Based on 1,3,5-Triarylpent-2en-1,5-Diones. Angew. Chem., Int. Ed. 2001, 40, 2640-2643.

(25) Minami, T.; Emami, F.; Nishiyabu, R.; Kubo, Y.; Anzenbacher, P., Jr. Quantitative Analysis of Modeled ATP Hydrolysis in Water by a Colorimetric Sensor Array. Chem. Commun. 2016, 52, 7838-7841.

(26) Yu, G.; Yan, X.; Han, C.; Huang, F. Characterization of Supramolecular Gels. Chem. Soc. Rev. 2013, 42, 6697-6722.

(27) Steed, J. W. Anion-Tuned Supramolecular Gels: A Natural Evolution from Urea Supramolecular Chemistry. Chem. Soc. Rev. 2010, 39, 3686-3699.

(28) Tu, T.; Fang, W.; Sun, Z. Visual-Size Molecular Recognition Based on Gels. Adv. Mater. 2013, 25, 5304-5313.

(29) Yamaguchi, S.; Yoshimura, I.; Kohira, T.; Tamaru, S.; Hamachi, I. Cooperation Between Artificial Receptors and Supramolecular Hydrogels for Sensing and Discriminating Phosphate Derivatives. J. Am. Chem. Soc. 2005, 127, 11835-11841.

(30) Yang, D.; Liu, C.; Zhang, L.; Liu, M. Visualized Discrimination of ATP from ADP and AMP Through Collapse of Supramolecular Gels. Chem. Commun. 2014, 50, 12688-12690.

(31) Wei, S.-C.; Pan, M.; Li, K.; Wang, S.; Zhang, J.; Su, C.-Y. A Multistimuli-Responsive Photochromic Metal-Organic Gel. Adv. Mater. 2014, 26, 2072-2077.

(32) Tam, Y.-Y.; Yam, V. W.-W. Recent Advances in Metallogels. Chem. Soc. Rev. 2013, 42, 1540-1567.

(33) Jung, J. H.; Lee, J. H.; Silverman, J. R.; John, G. Coordination Polymer Gels with Important Environmental and Biological Applications. Chem. Soc. Rev. 2013, 42, 924-936.

(34) Zhang, J.; Su, C.-Y. Metal-Organic Gels: From Discrete Metallogelators to Coordination Polymers. Coord. Chem. Rev. 2013, 257, 1373-1408.

(35) Piepenbrock, M.-O.; Lloyd, G. O.; Clarke, N.; Steed, J. W. Metal- and Anion-Binding Supramolecular Gels. Chem. Rev. 2010, 110, 1960-2004.

(36) Lloyd, G. O.; Steed, J. W. Anion-Tuning of Supramolecular Gel Properties. Nat. Chem. 2009, 1, 437-442.

(37) Fages, F. Metal Coordination to Assist Molecular Gelation. Angew. Chem., Int. Ed. 2006, 45, 1680-1682. 
(38) Fang, W.; Liu, C.; Chen, J.; Lu, Z.; Li, Z.-M.; Bao, X.; Tu, T. The Electronic Effects of Ligands on Metalcoordination Geometry: a Key Role in the Visual Discrimination of Dimethylaminopyridine and Its Application Towards Chemo-Switch. Chem. Commun. 2015, 51, 4267-4270.

(39) Fang, W.; Liu, C.; Lu, Z.; Sun, Z.; Tu, T. Tunable Reversible Metallo-Hydrogels: a New Platform for Visual Discrimination of Biothiols. Chem. Commun. 2014, 50, 10118-10121.

(40) Fang, W.; Liu, X.; Lu, Z.; Tu, T. Photoresponsive MetalloHydrogels Based on Visual Discrimination of the Positional Isomers through Selective Thixotropic Gel Collapse. Chem. Commun. 2014, 50, 3313-3316.

(41) Fang, W.; Sun, Z.; Tu, T. Novel Supramolecular Thixotropic Metallohydrogels Consisting of Rare Metal-Organic Nanoparticles: Synthesis, Characterization, and Mechanism of Aggregation. J. Phys. Chem. C 2013, 117, 25185-25194.

(42) Tu, T.; Fang, W.; Bao, X.; Li, X.; Dötz, K. H. Visual Chiral Recognition through Enantioselective Metallogel Collapsing: Synthesis, Characterization, and Application of Platinum-Steroid LowMolecular-Mass Gelators. Angew. Chem., Int. Ed. 2011, 50, 6601-6605.

(43) Tu, T.; Bao, X.; Assenmacher, W.; Peterlik, H.; Daniels, J.; Dötz, K. H. Efficient Air-Stable Organometallic Low-Molecular-Mass Gelators for Ionic Liquids: Synthesis, Aggregation and Application of Pyridine-Bridged Bis(benzimidazolylidene)-Palladium Complexes. Chem. - Eur. J. 2009, 15, 1853-1861.

(44) Tu, T.; Assenmacher, W.; Peterlik, H.; Weisbarth, R.; Nieger, M.; Dötz, K. H. An Air-Stable Organometallic Low-Molecular-Mass Gelator: Synthesis, Aggregation, and Catalytic Application of a Palladium Pincer Complex. Angew. Chem., Int. Ed. 2007, 46, 63686371.

(45) Murata, K.; Aoki, M.; Suzuki, T.; Harada, T.; Kawabata, H.; Komori, T.; Ohseto, F.; Ueda, K.; Shinkai, S. Thermal and Light Control of the Sol-Gel Phase Transition in Cholesterol-Based Organic Gels. Novel Helical Aggregation Modes as Detected by Circular Dichroism and Electron Microscopic Observation. J. Am. Chem. Soc. 1994, 116, 6664-6676.

(46) Zhang, M.; Meng, L.; Cao, X.; Jiang, M.; Yi, T. Morphological Transformation between Three-Dimensional Gel Network and Spherical Vesicles via Sonication. Soft Matter 2012, 8, 4494-5000.

(47) Gaussian 09 Revision A.02; Frisch, M. J.; Trucks, G. W.; Schlegel, H. B.; Scuseria, G. E.; Robb, M. A.; Cheeseman, J. R.; Scalmani, G.; Barone, V.; Mennucci, B. A.; Petersson, G.; Nakatsuji, H.; Caricato, M.; Li, X.; Hratchian, H. P.; Izmaylov, A. F.; Bloino, J.; Zheng, G.; Sonnenberg, J. L.; Hada, M.; Ehara, M.; Toyota, K.; Fukuda, R.; Hasegawa, J.; Ishida, M.; Nakajima, T.; Honda, Y.; Kitao, O.; Nakai, H.; Vreven, T.; Montgomery, J. A.; Peralta, J. E., Jr.; Ogliaro, F.; Bearpark, M.; Heyd, J. J.; Brothers, E.; Kudin, K. N.; Staroverov, V. N.; Kobayashi, R.; Normand, J.; Raghavachari, K.; Rendell, A.; Burant, J. C.; Iyengar, S. S.; Tomasi, J.; Cossi, M.; Rega, N.; Millam, J. M.; Klene, M.; Knox, J. E.; Cross, J. B.; Bakken, V.; Adamo, C.; Jaramillo, J.; Gomperts, R.; Stratmann, R. E.; Yazyev, O.; Austin, A. J.; Cammi, R.; Pomelli, C.; Ochterski, J. W.; Martin, R. L.; Morokuma, K.; Zakrzewski, V. G.; Voth, G. A.; Salvador, P.; Dannenberg, J. J.; Dapprich, S.; Daniels, A. D.; Farkas, O.; Foresman, J. B.; Ortiz, J. V.; Cioslowski, J.; Fox, D. J. Gaussian, Inc.: Wallingford, CT, 2009.

(48) Zhang, X.; Yin, J.; Yoon, J. Recent Advances in Development of Chiral Fluorescent and Colorimetric Sensors. Chem. Rev. 2014, 114, 4918-4959.

(49) Wu, J.; Liu, W.; Ge, J.; Zhang, H.; Wang, P. New Sensing Mechanisms for Design of Fluorescent Chemosensors Emerging in Recent Years. Chem. Soc. Rev. 2011, 40, 3483-3495.

(50) Wong, K. M.-C.; Yam, V. W.-W. Luminescence Platinum(II) Terpyridyl Complexes from Fundamental Studies to Sensory Functions. Coord. Chem. Rev. 2007, 251, 2477-2488.

(51) Tang, J.-L.; Li, C.-Y.; Li, Y.; Zou, C.-X. A Ratiometric Fluorescent Probe with Unexpected High Selectivity for ATP and Its Application in Cell Imaging. Chem. Commun. 2014, 50, 1541115414. 